\title{
RELATIONSHIP BETWEEN BRAND VALUE AND INCOME STATEMENT COMPONENTS: A PANEL TOBIT ANALYSIS ON BIST COMPANIES
}

\author{
DOI: 10.17261/Pressacademia.2021.1480 \\ PAP- V.14-2021(6)-p.23-27
}

\section{Cengiz Onder ${ }^{1}$, Elif Guneren Genc ${ }^{2}$}

${ }^{1}$ Istanbul Commerce University, Finance Institute, Department of Financial Economics, Istanbul, Turkey. cengiz.onder@istanbulticaret.edu.tr, ORCID: 0000-0002-5061-6343

${ }^{2}$ Istanbul Commerce University, Department of International Trade, Istanbul, Turkey. elifg@ticaret.edu.tr, ORCID: 0000-0001-5439-914X

\section{To cite this document}

Onder, C., Genc, E.G., (2021). relationship between brand value and income statement components: a panel Tobit analysis on BIST Companies. PressAcademia Procedia (PAP), 15, 23-27.

Permanent link to this document: $h$ ttp://doi.org/10.17261/Pressacademia.2021.1480

Copyright: Published by PressAcademia and limited licensed re-use rights only.

\section{ABSTRACT}

Purpose- The purpose of this study is to analyze the relationship between the brand value of enterprises and selected income statement components. In the study, the relationship between the sector in which the enterprises operate and the brand value is also examined. Methodology- In the study, the relationship between the brand values of 51 companies traded in Borsa Istanbul and the sales, international sales, operating profit and marketing expenses of these companies was examined by using the Panel Tobit model. The brand values of the companies were obtained from the Brand Finance Turkey 100 reports. The companies were classified in 12 different sectors then the sectoral impact on the brand value was also examined by using Panel Tobit model.

Findings- The analysis reveals that there is a significant and positive relationship between the brand values of the companies and their sales, operating profit and marketing expenses. On the other hand, there is not a significant relationship between international sales and brand value. In the study, it was also concluded that being operating in the logistics and transportation sector and the telecommunications sector is more significant than other sectors in terms of increasing the brand value of the companies.

Conclusion- The findings of the study can guide enterprises in determining financial management strategies to increase their brand value.

Keywords: Brand value, Panel Tobit model, Brand Finance Turkey, BIST, income statement

JEL Codes: C24, G32, M31

\section{MARKA DEĞERI VE GELIR TABLOSU BILEŞENLERI ARASINDAKI iLLiŞKi: BIST ŞiRKETLERI ÜZERINE PANEL} TOBIT YÖNTEMIYLE BIR ANALIZ

\section{ÖZET}

Amaç- Bu çalışmanın amacı işletmelerin marka değeri ile seçilmiş gelir tablosu bileşenleri arasındaki ilişkiyi araştırmaktır. Çalışmada ayrıca işletmelerin faaliyet gösterdiği sektör ile marka değeri arasındaki ilişki de araştırılmıştır.

Yöntem- Çalışmada Borsa İstanbul'da işlem gören 51 şirketin marka değerleri ile satışlar, yurtdışı satışlar, faaliyet karı ve pazarlama giderleri arasındaki ilişki Panel Tobit Yöntemi kullanılarak incelenmiştir. Şirketlerin marka değerleri Brand Finance Turkey 100 raporlarından elde edilmiştir. Şirketler 12 farklı sektörde sınıflandırılmış ve marka değeri üzerindeki sektörel etki de Panel Tobit Yöntemi ile incelenmiştir.

Bulgular- Yapılan analizler sonucunda şirketlerin marka değerleri ile satışları, faaliyet karı ve pazarlama giderleri arasında anlamlı ve pozitif bir ilişki bulunmuştur. Diğer yandan yurtdışı satışlar ile marka değeri arasında anlamlı bir ilişki bulunmamaktadır. Çalışmada ayrıca, lojistik ve ulaştırma sektörü ile telekomünikasyon sektörlerinde yer almanın şirketlerin marka değerini artırmada diğer sektörlere göre daha anlamlı olduğu sonucuna ulaşılmıştır.

Sonuç- Çalışmanın bulguları, işletmelere marka değerini artırmaya yönelik finansal yönetim stratejilerinin belirlenmesinde yol gösterici olabilir.

Anahtar Kelimeler: Marka değeri, Panel Tobit model, Brand Finance Turkey, BIST, gelir tablosu JEL Kodları: C24, G32, M31 


\section{GiRiş}

Literatürde marka değeri kavramının birden fazla tanımı bulunurken marka değeri ile ilgili 3 temel yaklaşım öne çıkmaktadır (Kim, Kim ve An, 2003). Müşteri temelli yaklaşım; marka değerini markanın insan zihninde yarattı̆̆ı olumlu düşünceler ve tüketicilerin o markaya ilişkin sahip olduğu bilginin farklılık yaratan etkisi olarak ifade etmektedir (Keller, 1993). Müşteri temelli yaklaşıma göre pazarlama faaliyetleri tarafından maddi olmayan bir varlık olarak yaratılan marka değeri (Aaker, 1991), şirketlerin tüketicilere sunduğu mal ve hizmetlerin değerini artıran veya azaltan, markanın ad veya sembol gibi belirleyici özelliklerine bağlı varlık ve yükümlülükler bileşkesidir (Akgün ve Akgün, 2014). Finansal temelli yaklaşıma göre marka değeri markalı bir üründen veya hizmetten elde edilecek nakit akışlarının bugünkü değeridir (Bahadir, Bharadwaj ve Srivastava, 2008). Simon ve Sullivan (1993)'a göre ise marka değeri markalı bir ürünün markalı olmayan bir üründen farklı olarak sağladığı ilave nakit akışıdır. Üçüncü marka değeri yaklaşımı olan karma yaklaşım finansal temelli ve müşteri temelli yaklaşımların bileşkesidir. Karma yaklaşıma göre marka değeri, ürün ve hizmetin kalitesi, müşteri bağılı̆̆ı, müşteri tatmini, finansal performansı ile markaya duyulan saygının bir bütünü olarak markanın nasıl algılandığıdır (Knapp, 1999).

Marka değerini ölçümleme faaliyetleri yürüten uluslarası şirketler marka değerlemede karma yöntemler kullanmaktadır. Brand Economics, Brand Finance, Brand Metrics, Brand Rating, Future Brand ve Interbrand gibi birçok uluslararası danışmanlık şirketi karma yöntemler kullanarak marka değerleme hizmetleri sunmaktadır (Özdemir ve Öncül, 2016).

Uluslararası danışmanlık firması Brand Finance, geliştirdiği marka değerleme modelinde gelecekte markadan doğması beklenen faaliyet karlarını esas almaktadır. Brand Finance markaya ilişkin finansal verilerle açıklanamayacak unsurları da dikkate aldığı çalışmasında gelecekte markadan beklenen karlıığı iskonto ederek markanın bugünkü değerini hesaplamaktadır. Brand Finance, ülkeler bazında ve küresel ölçekte değerleme hizmeti verdiği markaları ISO 10688 standardı doğrultusunda Hak Bedeli (Telif haklarından kurtulma) yöntemi kullanarak hesaplamaktadır. Hak Bedeli yöntemi, işletmenin sahip olduğu markayı bir hak bedeli karşılığında başkasına kullandırdığını varsayımına dayanmaktadır. Bu yöntemle, bir lisansörün markasını açık pazarda lisanslayarak elde edeceği kazanç esasından hareketle şirketin elde ettiği hasılata hak bedeli uygulayarak net marka değerine ulaşılmaktadır. Brand Finance marka değerleme metodolojisi Tablo 1'de verilmiştir (Brand Finance Turkey, 2018):

\section{Tablo 1: Brand Finance Marka Değerleme Metodolojisi}

\begin{tabular}{|l|}
\hline $\begin{array}{l}\text { Pazarlama yatııımları ve göreceli ağılıklandııılmış faaliyet performans ölçümleri üzerinden marka gücünün hesaplanarak } 0 \text { - } 100 \\
\text { aralığında skorlanması, }\end{array}$ \\
\hline Karşılaştııılabilir lisans anlaşmaları incelenerek her bir endüstri kolu için hak bedeli (royalty) aralığııın belirlenmesi, \\
\hline Marka gücü skoru ile hak bedeli çarpılarak hak bedeli oranının hesaplanması, \\
\hline Şirketin toplam satışları içerisinde markalı satışların payının belirlenmesi, \\
\hline Geçmiş satış verisi, piyasa analizleri ve ekonomik büyüme beklentileri dikkate alınarak şirketin gelecekteki satışlarının tespit edilmesi, \\
\hline Hak bedeli oranının gelecekteki satışlara uyarlanarak markaya ait satışların tespit edilmesi, \\
\hline Markaya ait satışlara uygulanan iskonto oranı ile şimdiki net marka değerinin hesaplanması. \\
\hline Kaynak: Brand Finance web sitesi, https://brandfinance.com/wp-content/uploads/1/brand_finance_turkey_100_2018.pdf (Erişim tarihi: 22.10.2021).
\end{tabular}

\section{LITERATÜR}

Muqaddas ve Ahmad (2016), 2011-2015 dönemini kapsayan çalışmalarında Interbrand tarafından her yıl açıklanan ilk 100 değerli marka arasında yer alan önde gelen 20 bilgi işlem (IT) şirketinin marka değerlerini etkileyen finansal faktörleri incelemişlerdir. Marka değerinin bağımlı değişken olduğu panel regresyon çalışmasında; reklam giderleri, araştırma giderleri ve şirketlerin aktif karlıı̆̆ı (ROA) bağımsız değişken olarak kullanılmıştır. Çalışmada kullanılan sabit etkili modele göre; reklam giderleri ve aktif karlıı̆ı̆ı şirketlerin marka değeri üzerinde anlamlı bir etkiye sahip olduğu, araştırma giderlerinin ise marka değerini etkilemediği sonucuna ulaşmışlardır.

Finansal göstergeleri esas alan bir diğer çalışmada Topuz ve Akşit (2016) Interbrand tarafından hazırlanan en değerli 100 küresel marka raporlarında 2001-2012 yılları arasında kesintisiz yer alan 31 global şirketin marka değerinin şirket değeri üzerindeki etkisini incelemiştir. Dengeli panel modelinin kullanıldığı çalışmada şirket değerini yansıttığı varsayılan hisse fiyat endeksi bağımlı değişken olurken, o şirketin marka değeri ile birlikte şirketin toplam varlıkları, defter değeri, toplam özkaynakları ve satışları bağımsız değişken olarak kabul kullanılmıştır. Uygulanan rassal etki modeli sonuçlarına göre marka değeri ve bir dönem gecikmeli marka değeri ile birlikte diğer bağımsız değişkenlerin şirket değeri üzerinde pozitif ve anlamlı bir etkisi vardır. Diğer yandan Şenol, Koç ve Ünlü (2019), 27 BiST şirketinin Brand Finance tarafından açıklanan 2009-2016 dönemi marka değerleri ile firma değerleri arasındaki ilişkiyi Panel VAR yöntemiyle incelemişlerdir. Çalışmanın sonucuna göre; marka değeri firma değerinin nedenidir, firma değerindeki değişiklikler marka değeri tarafından açıklanmaktadır ve firma değeri ile marka değeri arasında zayıf bir ilişki bulunmaktadır.

Jovanovic, Krsti ve Milanovic (2020), Interbrand marka değeri verisini kullanarak önde gelen 5 büyük global teknoloji şirketinin (Apple, Microsoft, IBM, Intel ve Cisco) seçilmiş piyasa göstergeleri ile marka değeri arasındaki ilişkiyi doğrusal regresyon yöntemiyle incelemiştir. 2012-2019 dönemini kapsayan çalışma bulgularına göre, marka değeri ile piyasa kapitalizasyonu, Tobin Q, piyasa defter değeri oranı ve hisse başına kazanç göstergeleri arasında pozitif ve anlamlı bir ilişki bulunmaktadır ve marka değeri bu yüksek teknoloji şirketlerinin performansını olumlu yönde etkilemektedir.

Bank, Yazar ve Sivri (2020) çalışmalarında, BiST 100 endeksinde yar alan ve 2007-2015 döneminde Brand Finance Türkiye marka değeri raporunda en az bir kere yer almış şirketlerden oluşturdukları güçlü marka portföyü ile bu raporlarda yer almayan diğer BiST 100 şirketlerinden oluşturdukları zayıf marka portföyünü, CAPM ile Fama ve French 3 faktörlü modeli kullanarak risk-getiri analizi ile 
karşılaştırmışlardır. Çalışma sonucuna göre; güçlü marka portföyü hissedarlarına anlamlı bir anormal getiri sağlamaktadır ve ayrıca zayıf marka portföyüne göre daha az piyasa riskine sahiptir. Çalısma ayrıca marka değerinin hisse senedi fiyatlarına piyasa tarafından tam olarak yansıtılmadığına ve buna bağı olarak piyasanın etkin olmadığına işaret etmektedir.

\section{VERI VE YÖNTEM}

Çalışmada şirketlerin finansal performanslarının marka değerlerine etkisini belirlemek amacıyla 2008-2012 döneminde Brand Finance Türkiye 100 marka değerleri raporunda yer alan ve Borsa Istanbul'a kote 51 şirketin marka değerleri ve bu şirketlerin finansalları kullanılmıştır. Şirketler belirlenirken belirtilen dönemde Brand Finance raporunda kesintisiz yer alan şirketler seçilmiş, bunların arasından spor şirketleri ve bankalar ayıklanmıştır. Ulaşılan 51 şirket bulunduğu sektörler de dikkate alınarak 12 farklı gruba ayrılmıştır.

Şirketlerin marka değerleri Brand Finance tarafından her yıl düzenli olarak açıklanan Brand Finance Turkey 100 raporlarından alınmıştır. Brand Finance, marka değerini belirlerken o şirketin bir önceki yıla ait finansal verilerini dikkate almaktadır. Açıklanan marka değerleri ABD doları (USD) cinsinden olup bir önceki yılın kapanış USD/TL kuruyla Türk Lirasına çevrilmiştir. Şirketlerin finansal performans verisi olarak kullanılan satışlar, faaliyet karı, yurtdışı satışlar ve pazarlama giderleri ise Kamuyu Aydınlatma Platformu internet sitesinden temin edilmiştir. Doğrusal regresyonun bağımlı değişkeninin (marka değeri) sadece belirli bir aralıkta gözlemlenebiliyor olması nedeniyle çalışmada sansürlü normal regresyon modeli olarak da bilinen Panel Tobit Modeli kullanıımışırı. Çalışmanın ana modelinde marka değeri (MD) bağımlı değişken, satışlar (SAT), faaliyet karı (FK), pazarlama giderleri (PAZGiD) ve yurtdışı satışlar (YDSAT) ise bir dönem gecikmeyle bağımsız değişken olarak kullanılmışır. Çalışmanın ikinci modelinde ise marka değeri üzerinde sektörel etkileri gözlemlemek amacıyla sektörel kukla değişkenler (D) de bağımsız değişken olarak modele dahil edilmiştir. Çalışmada kullanılan değişkenler Tablo 2'de tanımlanmıştı:

Tablo 2: Çalışmada Kullanılan Değişkenlerin Tanımları

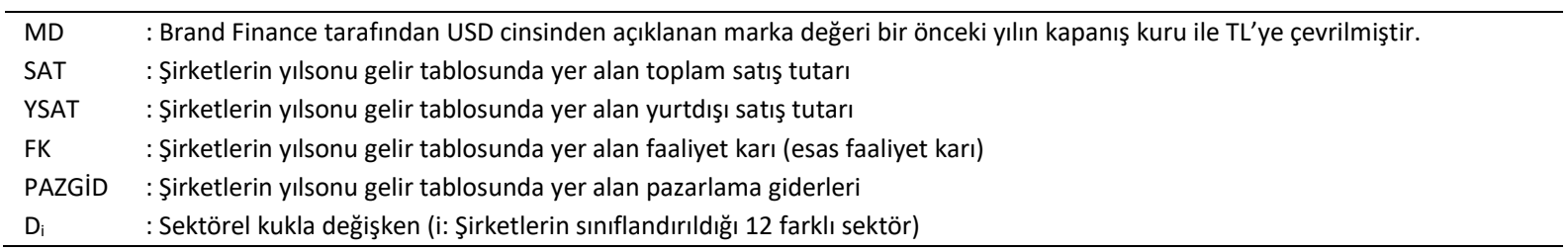

Sansürlü normal regresyon modeli olarak da bilinen Tobit model, lineer regresyonun bağımlı değişkeni sadece belirli bir aralıkta gözlemlenebiliyorsa uygulanabilir. Bir bağımlı değişkenin sansürlenmesi durumunda, sansürlenen bağımlı değişken ana kütleyi düzgün bir şekilde temsil etmez ve EKK regresyon ile tutarlı parametre tahmincileri elde edilmez. Bu nedenle Tobit modelinin tahmini için Maksimum Olabilirlik Yöntemi önerilir. Tobit modelde bağımlı değişken sürekli bir değişkendir ancak veri setinin bir bölümü olmadığı veya sınırlandırıldığı için eksik kalan gözlemlerin yerine sıfır ataması yapılmaktadır. Böylelikle gözlem seti kesikli bir özelliğe sahip olmaktadır (Maddala, 1983).

Tobin (1958) tarafından öne sürülen Tobit modelinde gözlemlenmeyen $y_{i}^{*}$ gizli değişken şu şekilde ifade edilir:

$y_{i}^{*}=x_{i}^{\prime} \beta+u_{i}$

Burada $\beta$ bilinmeyen parametre vektörüdür. Eğer $y_{i}^{*}>0$ ise $y_{i}^{*}$ gözlemlenebilir ve eğer $y_{i}^{*} \leq 0$ ise gözlemlenemez. Gözlemlenebilen $y_{i}$ şu şekilde ifade edilir:

$$
y_{i}=\left\{\begin{array}{l}
y_{i}^{*}>0 \text { ise } y_{i}^{*}=x_{i}^{\prime} \beta+u_{i} \\
y_{i}^{*} \leq 0 \text { ise }
\end{array}\right.
$$

Burada $u_{i} \sim N\left(0, \sigma^{2}\right)$ ve $y_{i}^{*} \sim N\left(x_{i}^{\prime} \beta, \sigma^{2}\right)$ seklinde dağı̆lıma sahiptir. Tobit modeli, panel veriler için de tahmin edilebilir. Panel Tobit modeli, doğrusal olmayan panel veri modellerinin tahmin yöntemlerinden biridir. Panel Tobit modelinde gizli değişken $y_{i t}{ }^{*}$ denklem (3)'teki gibi belirtilmiştir.

$$
\begin{array}{ll}
y i^{*}=\alpha i+x_{i t}^{\prime} B+u_{i t}, & i=1,2, \ldots, N, t=1,2, \ldots, T, \\
u_{i t}=v_{i}+\epsilon_{i t,} & \left(v_{i}^{\sim} N\left(0, \sigma_{v}{ }^{2}\right)\right),\left(\epsilon_{i t} \sim N\left(0, \sigma_{\epsilon}^{2}\right)\right)
\end{array}
$$

Denklem (3)'te gözlemlenen değişkenler denklem (4)'te belirtildiği gibi tahmin edilmiştir:

$y_{i t}=\left\{\begin{array}{l}y_{i t}{ }^{*}>0 \text { ise } y_{i}^{*}=x_{i t} \beta+u_{i t} \\ y_{i t}{ }^{*} \leq 0 \text { ise }\end{array}\right.$ 


\section{BULGULAR}

Çalışmada kullanılan değişkenlere ait tanımlayıcı istatistikler Tablo 3’te verilmiştir. Buna göre çalışmada gözlemlenen en düşük marka değeri 794 milyon TL, en yüksek marka değeri ise 11,7 milyar TL'dir.

Tablo 3: Değişkenlerin Tanımlayıcı İstatistikleri

\begin{tabular}{lcccc}
\hline & Ortalama & Standart Sapma & Minimum & Maksimum \\
\hline MD & 794.000 .000 & 1.430 .000 .000 & 24.344 .000 & 11.700 .000 .000 \\
SAT & 5.050 .000 .000 & 8.420 .000 .000 & 80.736 .151 & 75.100 .000 .000 \\
PAZGiD & 494.000 .000 & 1.060 .000 .000 & 799.178 & 8.020 .000 .000 \\
FK & 498.000 .000 & 988.000 .000 & -1.380 .000 .000 & 8.190 .000 .000 \\
YDSAT & 2.500 .000 .000 & 6.550 .000 .000 & 483.000 & 67.900 .000 .000 \\
\hline
\end{tabular}

Şirketlerin gelir tablosu bileşenlerinin ve ayrıca faaliyet gösterdikleri sektörün marka değerleri üzerindeki etkisinin incelendiği rassal etkili Panel Tobit modelin bulguları Tablo 4'te yer almaktadır:

Tablo 4: Rassal Etkili Panel Tobit Bulguları

\begin{tabular}{|c|c|c|c|c|}
\hline \multirow{2}{*}{$M D$} & \multicolumn{2}{|c|}{ Model 1} & \multicolumn{2}{|c|}{ Model 2} \\
\hline & Tobit Katsayıları & Marjinal Etkileri & Tobit Katsayıları & Marjinal Etkileri \\
\hline \multirow[t]{2}{*}{ Sabit } & -12.000 .000 & & -80.900 .000 & \\
\hline & (83.900.000) & & $(76.400 .000)$ & \\
\hline \multirow[t]{2}{*}{$S A T(-1)$} & $0,1088 * * *$ & 0,0536 & $0,0932 * * *$ & 0,0461 \\
\hline & $(0,0073)$ & & $(0,0114)$ & \\
\hline \multirow[t]{2}{*}{$F K(-1)$} & $0,2816 * * *$ & 0,1388 & $0,3105^{* * *}$ & 0,1536 \\
\hline & $(0,0635)$ & & $(0,0659)$ & \\
\hline \multirow[t]{2}{*}{ PAZGID(-1) } & & & $0,1335^{*}$ & 0,0660 \\
\hline & & & $(0,0773)$ & \\
\hline \multirow[t]{2}{*}{$\mathrm{D}_{\text {telekomünikasyon }}$} & & & $532.000 .000 *$ & 263.000 .000 \\
\hline & & & (308.000.000) & \\
\hline Dulaştırma ve lojistik & & & $965.000 .000 * * *$ & 478.000 .000 \\
\hline & & & $(369.000 .000)$ & \\
\hline
\end{tabular}

Çalışma sonucunda; gelir tablosu bileşenlerinin bağımsız değişken olarak kullanıldığı birinci modelde şirketlerin marka değerleri ile satışları ve faaliyet karı arasında anlamlı ve pozitif bir ilişki bulunurken marka değeri ile pazarlama giderleri ve yurtdışı satışlar arasında bir ilişki bulunmamıştır. Birinci modelde ayrıca şirketlerin faaliyet karının marka değeri üzerindeki marjinal etkisinin satışlarına göre daha fazla olduğu sonucuna ulaşılmıştır.

Marka değeri üzerinde sektörel etkilerin incelendiği ikinci modelin sonuçlarına göre; şirketlerin marka değeri ile faaliyet karı, satışları ve pazarlama giderleri arasında anlamlı ve pozitif bir ilişki bulunurken yurtdışı satışları ile marka değeri arasında bir ilişki bulunmamaktadır. İkinci modelde ayrıca, sektörel etkilerin dahil edilmesiyle birlikte faaliyet karının marka değeri üzerindeki marjinal etkisinin daha da arttığı sonucuna ulaşılmıştır. Sektörel etkiler dikkate alındığında ise telekomünikasyon ile ulaştırma ve lojistik sektörüne ait katsayılar anlamlı bulunmuştur. Bu durum, telekomünikasyon ile ulaştırma ve lojistik sektörlerinin marka değeri olduğu ve ayrıca bu sektörlerde yer almanın şirketler için marka değeri yarattığı ve ayrıca şirketlerin marka değerini arttırdığı şeklinde yorumlanabilir. Nitekim Brand Finance marka değeri raporlarında tüm dönemlerde ilk sıralarda yer alan Türk Hava Yolları ulaştırma ve lojistik sektörü için, aynı şekilde Turkcell de telekomünikasyon sektörü için güçlü marka olma özelliğine sahip şirketler olup, çalışma sonuçları bu durumu yansıtmaktadır.

\section{SONUÇ}

Çalışmamızın marka değeri arttırma ve marka değeri oluşturmak için şirketlerin izleyeceği finansal yönetim stratejilerini belirlemede yardımcı olacağını düşünüyoruz. Çalışmanın ayrıca marka değeri oluşturmak için hangi sektörlerde ilerlemek gerektiği konusunda da yol göstermesi beklenmektedir.

Çalışmamız Türkiye'de faaliyet gösteren şirketlerin marka değerleri ile onların gelir tablosu bileşenlerini konu almaktadır. Her ne kadar çalışmamızda yurtdışı satışlar ile marka değeri arasında anlamlı bir ilişki tespit edilmese de özellikle uluslararası tanınmış markalarla ilgili yapılacak benzer çalışmalarda farklı sonuçlara ulaşılacağını düşünüyoruz.

\section{KAYNAKÇA}

Aaker, D. 1991. Managing Brand Equity: Capitalizing on the Value of a Brand Name. New York: The Free Press.

Akgün, Ö.V. \& Akgün, A. (2014). Marka ve marka değeri olgusu: marka değerinin tespitine yönelik bir uygulama. Selçuk Üniversitesi Sosyal ve Teknik Araştırmalar Dergisi, 8, 1-13. 
Bahadir, S.C.,Bharadwaj, S.G. \& Srivastava, R.K. (2008). Financial value of brands in mergers and aquisitions: is value in the eye of the beholder?, Journal of Marketing, 72(6), 49-64.

Bank, S., Yazar, E.E. \& Sivri, U. (2020). The portfolios with strong brand value: more returns? lower risk?, Borsa Istanbul Review 20 (1), 64-79.

Jovanovic, M., Krstic, B., \& Milanovic, S., (2020). The ımpact of brand value on market performance indicators of high-technology enterprises. Facta Universitatis Series: Economics and Organization, 17(4), 317-328.

Keller, K.L. (1993). Conceptualizing, measuring and managing customer based brand equity. Journal of Marketing, 57(1), 1-22.

Knapp, D.E. (1999). Brand Mindset: Five Essential Strategies for Building Brand Advantage Throughout Your Company. A.B.D: McGraw-Hill.

Kim, H., Kim, W.G. \& An, J.A. (2003). The effects of consumer-based brand equity on firms financial performance. Journal of Consumer Marketing, 20(4), 335-351.

Maddala, G.S. (1983). Limited Dependent and Qualitative Variables in Econometrics. Cambridge University Press, U.S.A.

Mukaddas, M.F. \& Ahmad, I. (2016). Determinants of brand equity: an empirical study of IT ındustry. Practical Application of Science. 3(12), 555-560.

Özdemir, Ş. \& Öncül, M. (2016). Marka değerleme. Cumhuriyet Üniversitesi İktisadi ve İdari Bilimler Dergisi, 17(2), $205-224$.

Simon, C. \& Sullivan, M. (1993). The measurement and determinants of brand equity: a financial approach. Marketing Science, $12(1), 28-52$.

Şenol, Z., Koç, S. \& Ünlü, U. (2019). Marka değeri ile firma değeri arasındaki ilişki: Borsa İstanbul örneği. Ömer Halisdemir Üniversitesi İktisadi ve İdari Bilimler Fakültesi Dergisi, 12(3), 338-350.

Tobin, J. (1958), Estimation of relationships for limited dependent variables. Econometrica: Journal of the Econometric Society, $26(1)$, 24-36.

Topuz, Y.V. \& Akşit, N. (2016) The effect of the brand value on firm value: an empirical ımplementation to global brands. British Journal of Marketing Studies. 4 (1), 21-31.

www.brandfinance.com

www.kap.gov.tr

EKLER

Tablo E1: Sektör Gruplarına Göre BisT Şirketleri

\begin{tabular}{ll}
\hline \multicolumn{1}{c}{ Sektör } & Şirketler \\
\hline Bilişim ve Teknoloji & ARENA, ASELS, INDES, LOGO \\
Kimya ve Petrol Ürünleri & AYGAZ, DYBYO, ECILC, GOODY, \\
& MRSHL, \\
Toptan ve Perakende & ADEL, DERIM, DESA, MGROS, \\
Ticaret & ULKER, VAKKO \\
Otomotiv & ASUZU, FROTO, KARSN, OTKAR, \\
& TOASO, TTRAK \\
Demir Çelik ve İnşaat & BRSAN, EGPRO, EGSER, ENKAI, \\
& TAVHL \\
Ev Mobilya & YATAS
\end{tabular}

\begin{tabular}{ll}
\hline Sektör & Şirketler \\
\hline $\begin{array}{l}\text { Tekstil } \\
\text { Cam ve Porselen }\end{array}$ & $\begin{array}{l}\text { BOSSA, KORDS, SOKTS, YUNSA } \\
\text { KUTPO, SISE }\end{array}$ \\
Dayanıklı Tüketim & ALCAR, ARCLK, VESTL, VESBE \\
Telekomünikasyon & KAREL, NETAS, TCELL \\
Ulaştırma ve Lojistik & RYSAS, THYAO \\
Gıda ve İçecek & AEFES, BANVT, DARDL, KENT, KERVT, \\
& PENGD, TBORG, TATGD, TUKAS \\
\hline
\end{tabular}

